\title{
Utilization of Remote Experimentation in Mobile Devices for Education
}

\author{
http://dx.doi.org/10.3991/ijim.v6i3.2144 \\ W. Rochadel ${ }^{1}$, S.P. Silva ${ }^{1}$, J.B. Silva ${ }^{1}$, T.D. Luz $^{1}$ and G.R. Alves ${ }^{2}$ \\ ${ }^{1}$ Universidade Federal de Santa Catarina, Araranguá, Brazil. \\ ${ }^{2}$ Instituto Politécnico do Porto, Porto, Portugal.
}

\begin{abstract}
In this paper the authors intend to demonstrate the utilization of remote experimentation (RE) using mobile computational devices in the Science areas of the elementary school, with the purpose to develop practices that will help in the assimilation process of the subjects taught in classroom seeking to interlink them with the daily students' activities. Allying mobility with RE we intend to minimize the space-temporal barrier giving more availability and speed in the information access. The implemented architecture utilizes technologies and freely distributed softwares with open code resources besides remotes experiments developed in the Laboratory of Remote Experimentation (RExLab) of Federal University of Santa Catarina (UFSC), in Brazil, through the physical computation platform of the "open hardware" of self-construction type. The utilization of open code computational tools and the integration of hardware to the 3D virtual worlds, accessible through mobile devices, give to the project an innovative face with a high potential for reproducibility and reusability.
\end{abstract}

Index Terms-component; Remote experimentation; education; Mobile devices; Moodle; 3D Virtual Environment; Open source; Open hardware

\section{INTRODUCTION}

The paradigm of teaching and learning has been suffering significant changes in the last decades, fact that has been allowing the evolution, in part, of the education models. The change in the teachers and students profiles press for models where the actualization and permanent adaptation of educative action must adapt to news scenarios of learning, where the New Information and Communication Technologies (NICT) constitute in an unending fountain of alternatives.

On this context it is up to the Educational Institutions (EI) to know how to adapt themselves to the changes adopting the technologies as tools that allows them transcend out of classes, offering teaching alternatives where students have an opened window to their formation inside and outside university, allowing them to make their acquired competences stronger and to reach others that will give them an independent and effective learning with the technological, methodological, corporative and social competences.

The NICTs, because of their accessibility, have been favored in the development of new environments of support to collaborative learning, as the case of virtual envi- ronments in the educational context, that find subsidy to turn themselves on important agents in the enormous task to improve the teaching and learning as an objective to satisfy the demands and challenges of a globalized economy. The NICTs give new communication and interaction tools that are present in the daily life of students; however, those usually do not find a correspondence inside the educational environment. The educational world is out of rhythm with the technological revolution that is happening outside the classrooms in this moment.

The classrooms need to be transformed into opened learning centers that offer teaching-learning methodologies, mainly in the scientific-technological areas, based in practices that stimulate the ratiocination and that get closer to reality. The proper utilization of NICTs may offer the potential to reach the teaching vanguard.

The project here presented contemplates the development and implementation of a collaborative virtual environment of teaching-learning that embodies many technologies, as tridimensional projections, support and management of educational materials, remote experimentation allowing them to access, via Web, in the conventional way and also beyond mobile devices. The environment proposes the utilization of 3D social representations, with the objective to proportionate the access to information in a dynamic and interactive way in virtual environment closer to the physical reality of the students and then minimizing in part the distance between theory and practice and also contributing to increase the motivation of the students in the virtual learning assignments. To consecution of the objectives of this project we are using in its totality resources of technologies freely distributed and with open code (open source) softwares and experiments developed on RExLab from the utilization of the physical computation platforms of the "open hardware" kind.

With the purpose of attending the needs of actualization, the use of the mobile learning was chosen to do the interface between learning virtual environments and mobile devices, attending the principle of education of anyone, anywhere and anytime.

The environment here presented seeks to extend not only the classroom through remote experimentation, but also school with the utilization of the virtual 3D worlds with the objective of create more effective bonds of the academy in a global and dynamic round surroundings. To provide the possibility to overcome the barriers of the classroom means to seek a difference in relation to the 
simple use of virtual laboratories that only simulate experiments and do not interact with real equipment, where the results or the experiments manipulation do not reproduce steadfastly the reality. From a mobile device, with internet access, the student will be able to access anywhere at any moment the experiments available in the laboratories, interacting with the real equipments and checking the concepts that are studied in classroom, being able to relate the knowledge with the observation of experiments. Young people are immersed on NICTs and use the most diverse resources for sharing of knowledges and also for entertainment. Make the teaching-learning environment available is to seek to contextualize the living and the learning making the study more attractive when focusing it on the application.

When we propose the utilization of the virtual collaborative environment of teaching-learning that embodies many technologies as: tridimensional representations, support and management of teaching materials, remote experimentation and shared spaces of work that have as purpose to make the construction management and transference of knowledge easier, we have as a goal to develop actions that may promote the social appropriation of science and technology and the popularization of the scientific and technological knowledges and then stimulate the young people to insert themselves in the scientifictechnological careers and engineerings.

\section{MORE ATTRACTIVE ENVIRONMENTS FOR EDUCATION}

The teaching and learning are not any more limited to the works inside classrooms and the modalities of present and distant education begin to be strongly modified, challenging the Education Institutions (EI) to find new models for new situations. In this context, the teaching and the learning are not lonely activities and need to be treated as a cooperative efforts among the ones involved in this process, where the active participation and the interaction allows that the knowledge may emerge, from an active dialogue among the participants sharing their ideas and information.

In a society in permanent metamorphosis that has as motive force the NICTs we may accompany the evolution of a generation of human beings that grows in the middle of digital technologies and that learn really soon to access in a quick way an immense range of information and to communicate with other people. It is a new man, the digital native or Homo Zappiens [1]. This new man represents a great challenge for education, the one of built new models of teaching-learning syntonized with the available technologies for this new generation.

This new scenario suggests the redraw of the education creating new and interesting teaching opportunities. Opportunities those that consider the learning technology from environments that promote and support the creation of communities that are compatible, not antagonist, with the way that people learn. It is important to extend not only the classroom, but also the school and think as only one process the action (to do) and the creation of knowledge (to know). To be alert to the feedback and allow the personalization. That way, there may be created more effective bonds of the academy in a global and dynamic environs, a great way to explore for the consecution of those objectives is the use of the NICTs.
The School Cense of 2009 [2], which is a research made by the Education and Culture Minister of Brazil (MEC), showed that in High School only 25,1\% of the teachers that lecture the Physic subject have formation in the area and in the lasts years of Junior High this number falls to $5 \%$ of the teachers.

In the science subjects in elementary school, essential to the educational and professional formation, that have the intention of amplify the vision of the effects that are part of the daily life and to give a base to the Engineering studies, with common methods of teaching-learning and because of the lack of activities, the vision of the physical happenings remain only in abstract images of theory or that do not relate with practical. By not being able to make a connection, the subjects do not motivate students to follow in these areas, or even to build the knowledge, getting lost on the function to turn the subject enjoyable.

The subject of the science subjects, since the elementary school, must become the closest to the real, making part of the daily life with experiments and laboratories for practices, allowing a better perception of the physical effects that occur and attract the attention to the utility of the subject ministered in classroom. Besides this importance, the low availability of laboratories and the insufficiency of available resources to make experiments that help in the learning process, demotivate students to apply their knowledge, missing the relation of the observation of those subjects, discouraging them to follow the Engineering path increasing the evasion and indolence.

About the lack of interest of student in the physics teaching, apud [3]: "In physics education, a factor very evident by teachers and students as one of the reasons that contribute for a negative picture of physics is the mathematical language, considered many times as the big responsible for the school failure".

Since the students entering higher education are from a very poor high school, contributing for the deficit in the engineering courses where the entrants encounter themselves with subjects as Calculation, Algebra, Physics, among others. Where, in 2011, in Brazil [4] its calculated the lack of at least 75 thousand professionals graduated in the area, in all the country there are offered more than 300 thousand jobs, of those, only 120 thousand are taken, suffering yet a rate of $54 \%$ of evasion.

What is noticed is that, for not knowing the real utility of the scientific subjects, students do not get interested on continuing in these areas, or they find themselves with great difficulties on all levels of education, lacking interaction with the practical, which is not presented in classroom.

Seeking new attitudes that will provide new learning opportunities, where the use of the technological tools propitiates creative and innovative solutions, that will contribute in the formation process, building more effective bounds on universities.

\section{ENCOURAGING THE USE OF MOBILE DEVICES IN THE TEACHING-LEARNING PROCESS}

Each day, the mobile devices are becoming more accessible to the many social classes because of the price reduction that has been contributing to this accessibility. According to the Minister Fernando Haddad [5], beginning in 2012, the Ministry of Education of Brazil (MEC) will dis- 
tribute "hundreds of thousands" of tablets on Brazilian public schools with the objective of universalize and socialize the access of students to technology.

Nowadays the use of NICTs in the educative environment is restricted as a research environment, being like that, poor of utilities. It is needed that the insertion of those technologies may make the teaching-learning process more dynamic, offering the interaction of the student with more real experiments, since the primary, because it is at this that the basic subjects for the continuation and enjoyment of the courses in the Engineering and technologies are consolidated.

The availability of new forms of content such as 3D worlds, games, virtual learning environments, movies, and also different vehicles as tablets, smartphones and cellphones, are fundamental to the development of this new educational scenario. Those are resources that are already part of the students' daily life and are utilized for entertainment, fun, communication and for education, in the big part of times, just as a research way, with few diversifications of use and interactivity.

It is also noticed the affection of the students for social networks and for the content sharing, being constantly connected and this is the main motivation for the presentation of the model of the application here purposed, because it is sustained in the idea and fascination, of students, for technologies. With this motivation, it is expected to attract students for the sharing of their knowledge in any place from their mobile devices, not only at school, but also in their residences, on the street, beyond friends and with family, being able to present their knowledge to others and this way presenting the sciences as something closer from real life.

The intention with that is to narrow the learning relations of the concepts presented in classroom with the dayto-day, encouraging the thirst for the find out and mobilizing students for the interest on development of skills that may be useful and that seek to put in proof the assimilated concepts.

\section{REMOTE EXPETIMENTATION AS EDUCATIONAL SUPPORT}

In relation to the remote laboratories [6]-[8] it is said that they are those where the elements and the experiments are real, but the access is virtual. We find the following advantages in remotes laboratories;

- $\quad$ There is direct interaction with real equipment;

- $\quad$ The information are real;

- There is no time or space restriction;

- It has medium assembly, utilization and maintenance costs;

- There is online feedback of the experiments.

The use of remotes environments brings comfort, safety and economy in a general way, being able to control different tasks, as sensors, circuits and safety systems, the students are also able to observe dynamic phenomenons that are many times hard to explain through written material, making a realistic approach to solve problems.[9][11]

The low cost resources implemented are accessible and may easily be reproduced in other institutions, giving an extension of the utilization of the laboratories and exhibi- tion of the experiments produced on those for more users in different places, showing the achievements of the researchers group. This sharing diversifies and extends the advantage of experiments, allowing many phenomenons and concepts studied in classroom to show the practical advantage of knowing them.

Since 1996, RExLab utilizes low cost resources, prioritizing the implementation of those with open-source and open-hardware ways, having as objective the technological development of the country and the social inclusion, contributing to promote the capacitation in the citizens and professionals formation, with the development of remote actions to the amplification of the reach of those provided services.

\section{VIRTUAL LEARNING ENVIRONMENT}

According to Pereira [12], Virtual Learning Environment (VLE) consists in an option of media that has been used to mediate the teaching-learning process to distance.

This way, the RExLab makes available the activities and the teaching materials on Moodle (Modular ObjectOriented Dynamic Learning Environment) [13] that allows the development of dynamic web sites, beyond sharing educational content, it still owns resources as chats, forums and personalized activities in different questionnaire ways.

One of the ideals of the implementation of this learning environment is to supply a building learning, where the learning protagonist is the student, through the sharing experience among the participants, in contraposition to the traditional knowledge from the teacher transfer model.

Moodle can still give to its users a bigger facility in the productions and distribution of contends, total learning management, realization of students' evaluation, access control and technological support for the availability of contends according to the pedagogical model.

\section{MOBILE LEARNING}

The use of mobile devices on education, the Mobile Learning, or just m-Learning, comes from since the access to internet from cells and other devices caused an exponential growth in the quantity of information published in social network, accompanying these development, educational institutions also create among their websites an opening so that people will have an optimized access through any device.

So it was implemented a model of pedagogical laboratories practices accessible to students, therefore, to use some modules on Moodle, and bringing them together with programs in web language that allows these access of mobile devices to the learning material, teachers material, streaming visualization in real time of remotes experiments and practical exercises contemplating a constructive learning. 


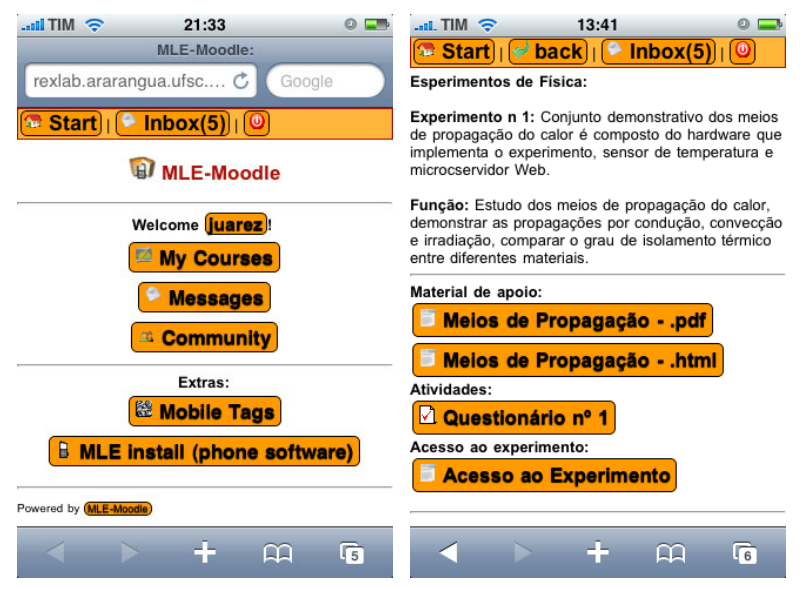

Figure 1. MLE Interface accessing Moodle of RExLab.

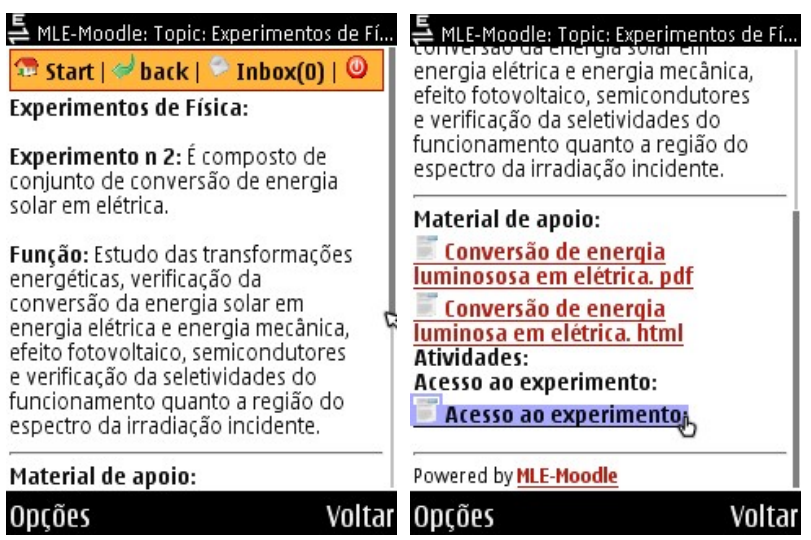

Figure 2. Teaching material available.

It is possible to observe in fig. 1 the visualization in an Apple iPhone 3G iOS 4.2 of the interface of ${ }^{1} \mathrm{MLE}-$ Moodle (Mobile Learning Engine Moodle), WML, PHP and MySQL. The access of the MLE-Moodle from an open-source module, free and customizable, linked to Moodle. The specifications may be adapted as necessary; with cellphones it is performed by a device browser, or it is possible to use a special module to help in the learning process with mobile devices. [14]

With the plugin MLE installation on Moodle server, it was possible to utilize those friendly interface resources to mobile devices from the browser of the device. This way the student has access to the teaching materials that may be studied at any moment and make their activities.

\section{TEACHING MATERIAL}

On RExLab's Moodle there are available teaching materials related to the subject that relates to the experiment, theoretical concepts are applied, calculus and other practical example of the application showing how the experiment works.

It is important that the teaching material profits the available learning objects varying their use, to offer practices in different models creating diverse situations.

As shown in fig. 2, print screen of a Nokia N73 Symbian OS S60v3, the material can be downloaded to the

1Avaliable at: mle.sourceforge.net/

device and visualized with the visualizing software re

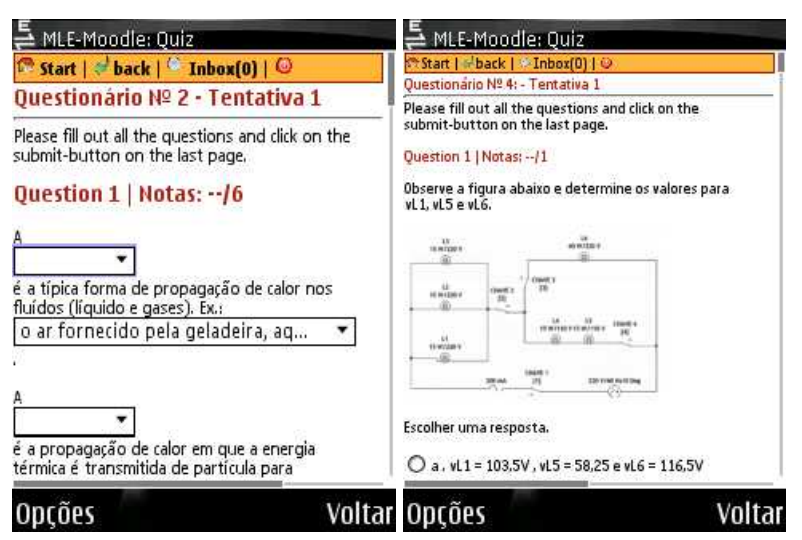

Figure 3. Access to the activities

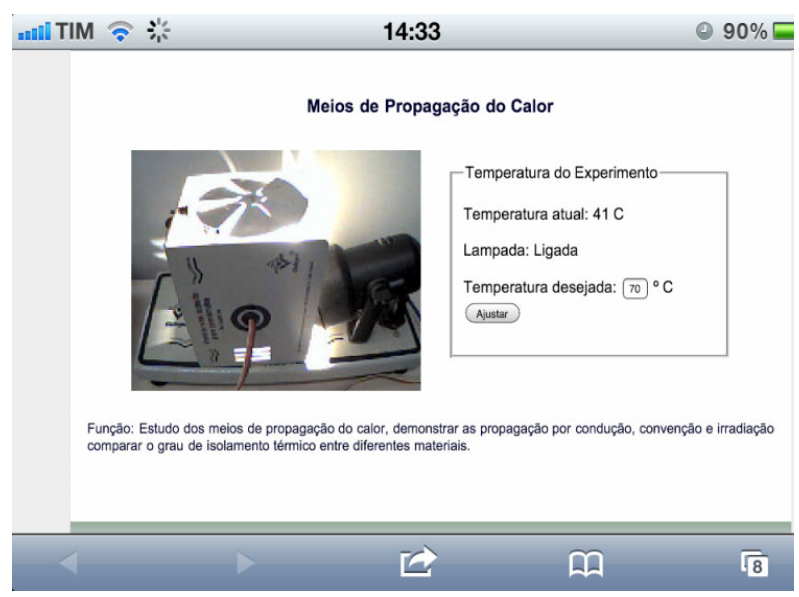

Figure 4. Demonstration of Remote Experiment on Apple iPhone $3 G$.

sources of slide presentations, Portable Document Format (PDF) or in the browser.

There are also activities available in several formats as multiple choice quiz, fulfill phrases, columns association, among others, these exercises are developed as support and evaluation material, seeking to associate the practice of the experiments, the studied concepts and the others associated phenomenons.

\section{REMOTE EXPERIMENTATION}

The interaction with the experiments happen via web browser, the sites are developed in PHP and use Java Script to the interface. Once activated, data is sent to the micro-server Web, the interlink of the experiments is done with relays that add keys and make the same ones to work.

All this procedure can be visualized in real time through a camera that, as demonstrated in figure 3, may be watched from internet, by computer or any mobile device that allows the streaming visualization of the camera.

Thanks to the IP addresses of the micro-servers Web it is possible to activate the experiments also via $3 \mathrm{D}$ virtual worlds, the laboratory has a virtual environment in third dimension that utilizes the ${ }^{2}$ Open Simulator as server, where graphical representations replicate the experiments and they can be activated in real time, also in that environment. The Moodle itself owns a tool of integration with 3D virtual worlds, the ${ }^{3}$ Sloodle, that way the Moodle's tools appear in graphical representations on OpenSim. [15] 


\section{IMPLEMENTED ARCHITECTURE}

Following the above descriptions of the mains parts implemented in the remote experimentation laboratory, it is possible to have an idea of the whole implementation.

For the proposed objectives it was used the open source resource of the Learning Management System of Moodle, remotes experiments developed in the Laboratories of Remote Experimentation (RExLab) and the platforms open hardware Micro-server. The utilization of open code computational tools and the mobility of devices as tablets, smartphones, cellphones, among others, brings to education an innovative application and with easy access in different regions.

The RExLab seeks to utilize softwares and hardwares freely distributed so the acquisition and maintenance costs will be low, and then making available a powerful teaching tool, since that in Brazil it is hard to exist physics laboratories in schools.

Releasing these accesses so they can be visualized in many kinds of platforms as web-browsers, mobile devices and 3D virtual worlds is part of the teaching tool ideology created in an extensive way, so it attends to diverse kinds of groups and that both has the capacity to access and obtain the knowledge inside their social context.

\section{FUTURE IMPLEMENTATION}

To the visualization of $3 \mathrm{D}$ virtual environments in computers they utilize visualizing softwares as the Imprudence Viewer and Hippo OpenSim, and are being developed visualizers to mobile devices, such as 3Di OpenSim [16], in its free version the Open Viwer that is already available, nevertheless, this software still do not show the avatars and graphical characteristics of the virtual world in its totality.

When the use of platforms such as this one is in their beta version, we can seek and test the compatibility of our $3 \mathrm{D}$ portal so it can also be used on mobile devices.

The Fig. 6 display shows the Visualization of the virtual environment of UFSC and of the resources provided by the Viwer software in a Sony Ericsson Xperia X8 Android OS 2.1

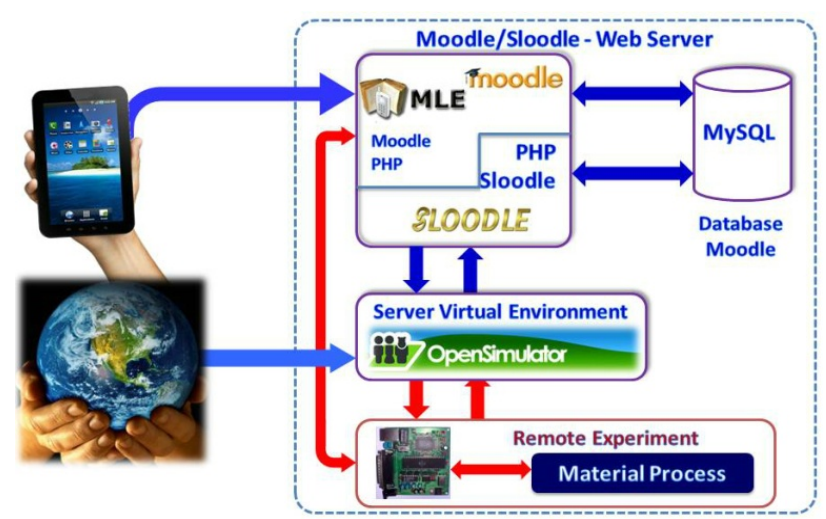

Figure 5. RExLab Implemented Architecture.

\footnotetext{
${ }^{2}$ Open Simulator - free version of Second Life

${ }^{3}$ Sloodle - Simulation linked Object Dynamic Learning Environment, a mashup between virtual world and Moodle.
}

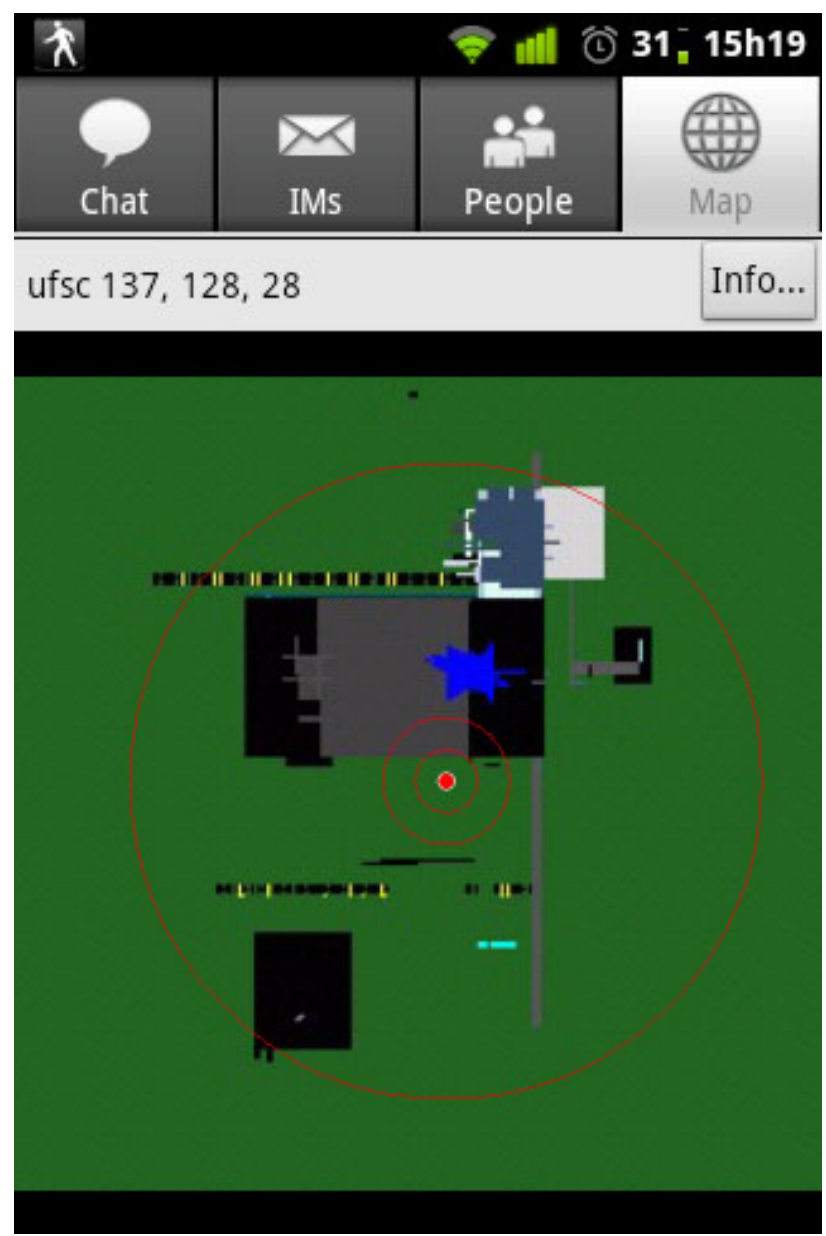

Figure 6. Visualization of the virtual environment of UFSC in a Mobile Devices with Android OS.

\section{CONCLUSION}

The inclusion of the mobile devices in the educational environment focused on the experiments allows to project a better productivity in the teaching, making it more effective and applied to the daily life of the students. With the educational purpose ordering to increase the flexibility and the collaborative reach in the teaching-learning activities, because the remote experimentation laboratories can proportionate to students an approach of this with the real world, while devices make the access easier.

The scenario brought by NICTs is of significant changes which allows a continuous evolution that involves different areas and break paradigms. Demanding fast adaptation, actualization to the needs, where effective tools that contribute and complement the process are created, in an even more appellative way, as interactive and collaborative environments.

It is known that laboratories are important environment for education, because they present in a more practical way the theoretical concepts approaching students to the utility of them, due to the lack of laboratories by part of the institutions this resource of availability of the remote access to the laboratorial practices can be accessed by different institutions, besides, students interact more at each time with the world.

The mobility in the connectivity of the society, the rush in information actualization and the sharing and urge to 
accompany the technological innovations demand challenges for the future of education. Since now, it is purposed this tool that already faces this precept of the new generations contextualizing themselves, being more innovative in it.

However it is believed that the present project has great potential and applicability; because this innovation may represent significant results regarding the motivation of students in relation to provide segments on their scientifictechnological studies.

\section{REFERENCES}

[1] W. Veen, B. Vrakking, "Knowing Homo Zappiens”, in Homo Zappiens: Student in the digital age, Porto Alegre, Brazil: Ed. Artmed, 2009, pp. 89.

[2] P. Borges, C. Rocha. (2010, Jun.). Half a million teachers give lessons without ideal training. Último Segundo. São Paulo, Brazil [Online]. Available: http://ultimosegundo.ig.com.br/educacao/ meio-milhao-de-docentes-da-aulas-sem-formacaoideal/n1237653160064.html

[3] A. R. P. Ataide, A. R. da S. Paulino, A. F. da Silveira, and E. P. Bento, "Physics, The 'Monster' of High School: Student Voice”. Presented at XVI National Symposium on Physics Education [Online]. Available: http://www.sbf1.sbfisica.org.br/eventos/snef/ xvi/cd/resumos/T0138-1.pdf

[4] C. Fonseca. Lack of engineers in Brazil: a deficit reaches more than 75.000 professionals. Ecaderno [Online]. Available: http://www.ecaderno.com/profissional/mercado-de-trabalho/3835/ faltam-engenheiros-no-brasil-deficit-chega-a-mais-de-75-milprofissionais-.html

[5] A. Dias. (2011, Jul.). MEC will distribute tablets to public school students in 2012. Espaço Educador[Online]. Available: http://espacoeducadoremacao.blogspot.com/2011/09/mec-vaidistribuir-tablets-para-alunos.html

[6] J. Ma, J.V. Nickerson. (2006, Sep.). Hands-On, simulated, and remote laboratories: A comparative literature review. ACM Computing Surveys. v.38, n.3.

[7] J.B. Silva, "On the use of remote experimentation to support collaborative learning environments”, Doctor thesis, Eng., UFSC, Florianópolis, SC, 2007.

[8] S. Paladini, J.B. Silva, J.B, G.R. Alves; B.T. Fischer and J.B. Alves. "Using Remote Lab Networks to Provide Support to Public Secondary School Education Level”. presented at 11th IEEE International Conference on CSEWORKSHOPS '08. Computational Science and Engineering Workshops. São Paulo, SP, 2008.

[9] T. Hampel, H. Selke and S. Vitt. "Deployment of simple usercentered collaborative technologies in educational institutions experiences and requirements”. Presented at 14th IEEE International Workshops on Enabling Technologies. Infrastructure for Collaborative Enterprise. Linköping, Sweden, 2005.
[10] Z. Nedic, J. Machota, A. Nafalski. "Remote laboratories versus virtual and real laboratories”. Presented at 33rd annual frontiers in education conference. Boulder, CO, 2003.

[11] J.E. Corter, J.V. Nickerson, S.K. Esche and C. Hassapis. (2007, Aug.). Constructing reality: a study of remote, hands-on, and simulated laboratories. ACM Transactions on Computer-Human Interaction. Vol 14, No 2.

[12] L.D. Feisel and A.J.Rosa. (2005, Jan.).The role of the laboratory in undergraduate engineering education. Journal of Engineering Education, Vol 94, No 1. [Online]. Available: http://www.mendeley.com/research/the-role-of-the-laboratory-inundergraduate-engineering-education/

[13] A. C. Pereira, "Virtual learning environments" in Virtual learning environments in different contexts, 1th, Ed. Ciência Moderna, Rio de Janeiro, RJ, 2007, pp. 5.

[14] M. Douguiamas. (2007, Jun. 14). "Moodle; a case study in sustainability”. OSS Watch [Online]. Available: http://www.osswatch.ac.uk/resources/cs-moodle.xml.

[15] R. S. Patric, M. D. Roseclea. (2009, Dec.). “Mobile Learning Engine Moodle (MLE - Moodle): das funcionalidades a validação em curso a distância utilizando dispositivos móveis”. Renote [Online]. Available: http://seer.ufrgs.br/renote/article/view/14026

[16] J. Kemp, D. Livingstone. (2006, Oct). "Putting a Second Life "metaverse"skin on leaning management systems (Sloodle whitepaper)” Sloodle [Online]. http://www.sloodle.org/whitepaper.pdf

[17] S. Koike (2010, Jun.).3Di Develops World-First Android- and OpenSim-Based. $3 \mathrm{Di}$ [Online]. Available: http://3di.biz/en/news/2010061001.html

\section{AUTHORS}

W. Rochadel, Undergraduate in Information and Communication Technologies, UFSC - Campus Araranguá, (wr.rochadel@gmail.com).

S.P. Silva, Undergraduate in Information and Communication Technologies, UFSC - Campus Araranguá, (silvana_piressilva@ hotmail.com).

J.B. Silva, Adjunct Professor, UFSC - Campus Araranguá, juarezbs.silva@gmail.com).

T.D. Luz, Undergraduate in Energy Engineering, UFSC - Campus Araranguá, (dollzinha_luz@hotmail.com).

G.R. Alves, Adjunct Professor, ISEP - School of Engineering - Polytechnic of Porto, (gca@isep.ipp.pt).

This article is an extended version of a paper presented at the International Conference IEEE EDUCON2012, held at University Mohammed V Souissi, Marrakesh, Morocco in the period of 17-20 April, 2012. Received 15 June 2012. Published as resubmitted by the authors 24 June 2012. 